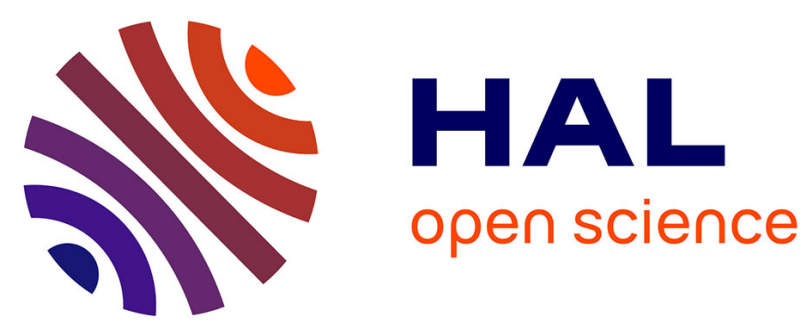

\title{
Ethnic in-Group Evaluation and Adhesion to Acculturation Ideologies: The Case of Moroccan Immigrants in France
}

Constantina Badea, Abdelatif Er-Rafiy, Peggy Chekroun, Jean-Baptiste Légal, Patrick Gosling

\section{To cite this version:}

Constantina Badea, Abdelatif Er-Rafiy, Peggy Chekroun, Jean-Baptiste Légal, Patrick Gosling. Ethnic in-Group Evaluation and Adhesion to Acculturation Ideologies: The Case of Moroccan Immigrants in France. International Journal of Intercultural Relations, 2015, 45, pp.47-55. 10.1016/j.ijintrel.2015.01.003 . hal-01473231

\section{HAL Id: hal-01473231 \\ https://hal.parisnanterre.fr/hal-01473231}

Submitted on 7 Jan 2019

HAL is a multi-disciplinary open access archive for the deposit and dissemination of scientific research documents, whether they are published or not. The documents may come from teaching and research institutions in France or abroad, or from public or private research centers.
L'archive ouverte pluridisciplinaire HAL, est destinée au dépôt et à la diffusion de documents scientifiques de niveau recherche, publiés ou non, émanant des établissements d'enseignement et de recherche français ou étrangers, des laboratoires publics ou privés. 


\section{Ethnic in-group evaluation and adhesion to acculturation ideologies: The case of Moroccan immigrants in France}

Constantina Badea, Abdelatif Er-rafiy, Peggy Chekroun, Jean-Baptiste Légal, Patrick Gosling

\section{Acculturation ideologies in France}

Since the French revolution, France has emphasized equality for all individuals, independently of their social, cultural and religious origins. This position does not recognize specific rights for any minority, be it ethnic, linguistic or religious. 
Through fear of communitarianism, which refers to strong allegiance to one's own ethnic or religious group or community rather than to the nation-state as a whole, all "specificities" are relegated to the private domain. The official acculturation ideology is "assimilation-citizenship" (Sabatier \& Boutry, 2006) which encourages immigrants to adopt French culture and does not allow them to defend any specific rights. This mixture between assimilation and citizenship is ambiguous. On the one hand, assimilation requires immigrants to abandon their own culture to the benefit of the language, values and customs of the majority group. Many studies have shown that adhesion to this acculturation ideology by the majority group members is associated with greater prejudice against immigrants (Badea, 2012; Levin et al., 2012; Wolsko, Park, \& Judd, 2002). On the other hand, citizenship promotes equality between French citizens and the respect of democratic values by all individuals independently of their social, ethnic or religious origin (Kamiejski, Guimond, De Oliveira, Er-rafiy, \& Brauer, 2012). Assimilation - citizenship sees the maintenance of cultural rights as an obstacle to equal rights in other domains. In other words, individuals must renounce their cultural specificities in order to be more easily assimilated into the host culture (Guimond, 2010). In this research we separately and respectively examine adhesion to assimilation and to citizenship ideologies (see for example, Kamiejski et al., 2012).

Officially monolingual and secular, France is in reality multilingual, multicultural and multireligious (Sabatier \& Boutry, 2006). In this multicultural context, even if the official immigration policy is one of assimilation - citizenship, other acculturation ideologies such as multiculturalism and secularism are promoted in French political discourse. The acculturation ideology of multiculturalism defends the idea of a multiple cultural identity, where specific cultures and the national culture coexist harmoniously. Partisans of multiculturalism think that only someone who feels safe in his/her own culture can be tolerant and generous towards others. Allowing minority groups to maintain their cultural and linguistic speci-ficity becomes a value of the majority group. Majority group members who prefer multiculturalism express less prejudice against immigrants (Badea, 2012; Levin et al., 2012; Wolsko et al., 2002). Multiculturalism shares with citizenship the idea of equality (between cultures and between individuals respectively). It is important to mention that multiculturalism is associated with positive intergroup attitudes in France. In other contexts such as Former Soviet Union, Japan and Mauritius, the majority group members can use multiculturalism to justify their dominant position and minorities can use assimilation to challenge inequality (Antonova, 2005). Concerning secularism ("laïcité"), this ideology requires religion and politics to be separate (Kamiejski et al., 2012). During the debate on national identity in France in 2009, initiated by the government, discourses conflated religion and ethnic identity. Secularism was widely evoked during the debate which led to the law against the Islamic veil (Bauberot, 2010). The veil ban is not respected by all members of Islamic minority and sanctions can lead to incidents such as the one recently seen in a Paris suburb (Le Monde, 22nd of July, 2013). Adhesion to secu-larism by the members of the majority group can be linked to negative attitudes towards immigrants (Kamiejski et al., 2012).

In this research, we look at whether adhesion to these acculturation ideologies (assimilation, citizenship, multiculturalism and secularism) by the members of a minority group shapes their evaluation of the ethnic in-group and of the majority out-groups. We take the example of Moroccan immigrants in France. The Moroccan community accounts for more than one million immigrants, living in the Paris region and around other big towns such as Clermont-Ferrand and Marseille. Most of them are Muslim and like other Muslims, they are the target of anti-immigrant sentiment in France (Badea et al., 2011). Many works of research show that Moroccans score high on positive attitudes towards their ethnic group (Badea et al., 2011; Sabatier, 2008) and their attitudes against Moroccans and French people are negatively correlated (Sabatier, 2008). It is possible for this group to show various patterns of group evaluation in line with their adhesion to acculturation ideologies.

Few studies have examined minorities' preferences for different acculturation ideologies and the link between these preferences and the evaluation of their own groups. In a study carried out in the Netherlands, Verkuyten(2005) demonstrated that the more Turkish immigrants endorsed assimilation ideology, the more they displayed negative in-group evaluation. In contrast, the more minority group members endorsed multiculturalism, the more they showed positive in-group evaluation. In a recent study in France, Kamiejski et al. (2012) showed that immigrants of Maghrebi origin, who adhere strongly to the principle of citizenship, evaluate North Africans as favourably as they evaluate French people, compared to those who adhere weakly to this acculturation ideology and who show an intergroup bias. When passively submitted to an assimilation ideology, minority members can also show a less favourable evaluation of their ethnic group. In a Canadian study, Wright and Taylor (1995) showed that Inuit children educated in a majority group cultural context (i.e. assimilation) evaluated Inuits less favourably than Canadians, compared to Inuit children educated in an environment promoting their own culture (i.e. multiculturalism).

\section{Acculturation ideologies and ethnic in-group evaluation}

Research shows that socialization plays an important role in the transmission of attitudes towards minority groups. "Participating in a culture means, at least in part, learning and accepting what the culture believes about one's own and other groups" (Mackie, Hamilton, Susskind, \& Rosselli, 1996, p. 60). Politics of immigration legitimize relationships between majority group members and immigrants (Bourhis, Moïse, Preault, \& Senecal, 1997). They can be at the origin of the "normative discourse" of immigrants' acculturation in a country (Guimond, de la Sablonnière, \& Nugier, 2014). Through a socialization process, Moroccan immigrants can learn what French society believes about their own and other ethnic groups (Mackie et al., 1996). In a study carried out in France (Dambrun, Gatto, \& Roche, 2005) Moroccan children show a more positive 
evaluation of the majority out-group, though only with implicit measurements. Authors interpret this result as providing support for the theoretical approach whereby children who are members of stigmatized ethnic groups internalize their "bad reputations".

However, minority group members do not always show a negative evaluation of their own group, even when they were socialized in a majority dominant culture (Guimond, 2010). Other factors, such as the possibility of joining the majority group (Guimond, Dif \& Aupy, 2002; Guimond \& Palmer, 1993), the tendency to justify the social system (Jost \& Banaji, 1994), or the adhesion to acculturation ideologies (Verkuyten, 2005; Ramos et al., 2013) can explain the variation in in-group evaluation among minority-group members. Moreover, group evaluation can be affected by social desirability norms (Reicher \& Levine, 1994). Moroccan immigrants can show positive attitudes towards the majority out-group in order to offer a positive image of themselves in the eyes of the investigators (Reicher \& Levine, 1994; Spears, Jetten, \& Doosje, 2001). Investigating implicit group evaluation minimizes the effect of social desirability and impression strategies (Jost, Pelham, \& Carvallo, 2002).

In this paper we examine how perception of the legitimacy of acculturation ideologies shapes immigrants' evaluation of the ethnic in-group and of the majority out-group. It is possible that the more immigrants perceive assimilation or secularism as being legitimized, the less they appreciate their in-group. That might be because in France, as in other countries, adhesion to assimilation or secularism is positively related to negative intergroup relations (Levin et al., 2012; Kamiejski et al., 2012). Socialized in a context where the majority culture is widely promoted, immigrants can think that the hierarchy of cultural groups is legitimized and that renunciation of ethnic group specificities is justified. "Subordinate groups often seem to internalize a wider social evaluation of themeselves as "inferior" or "second class [. . .]. Yet, under some conditions at least, low social status seems to be correlated with an enhancement, rather than a lessening, of positive out-group attitudes" (Tajfel \& Turner, 1979, p. 37; see also Rubin \& Hewstone, 2004). From this point of view, perception of the legitimacy of acculturation ideologies and its negative consequences on in-group evaluation might be the result of immigrants' socialization in a context not favourable to immigration.

Alternatively, immigrants might be following a strategy of individual mobility. According to social identity theory (Tajfel \& Turner, 1979), if intergroup frontiers are permeable, minority group members can try to move into the majority group by adopting its characteristics, norms and values. Ellemers (2001) has already shown that individual upward mobility can be accompanied by a perception of the legitimacy of intergroup relations (the case of women who are successful in maledominated organizations). From this point of view, immigrants' evaluation of groups and their perception of the legitimacy of acculturation ideologies favourable to the host country (assimilation, secularism) might reflect their wish to be part of the majority group.

\section{Overview of the present research}

We present two studies: in the first, we measure adhesion to different acculturation ideologies and group evaluation among Moroccan immigrants. We expect a negative correlation between in-group liking and adhesion to assimilation or secularism: The more immigrants prefer these ideologies, the less they show a positive evaluation of Moroccan peo-ple. We also expect a positive correlation between out-group liking and adhesion to assimilation or secularism: The more immigrants prefer these ideologies, the more they show a positive evaluation of French people. Finally, we expect a positive correlation between group liking and adhesion to multiculturalism or citizenship: The more immigrants pre-fer these acculturation ideologies, the more they show a positive evaluation of their in-group and of native French people.

In the second study, we experimentally manipulate acculturation ideology and we measure perceptions of the ideology's legitimacy and group evaluations at both explicit and implicit levels. We use an IAT (Implicit Association Test, Greenwald, McGhee, \& Schwartz, 1998) to measure attitudes at the implicit level. We hypothesize that in-group liking is lower than out-group liking in assimilation and secularism conditions compared to citizenship and multiculturalism conditions. The effect of acculturation ideology on group evaluation is mediated by the perception of legitimacy: the more immigrants perceive assimilation and secularism as being legitimized, compared to multiculturalism and citizenship, the less they show in-group liking. We formulate this hypothesis for both explicit and implicit measures.

\section{Study 1}

\subsection{Method}

\subsubsection{Participants}

The sample consisted of 101 participants who had parents of Moroccan origin. Fifty-six participants reported that their mother tongue was French, suggesting that they were immigrants of second generation and, 45 participants noted that their mother tongue was Moroccan. Median age was 35.49 years old, and ages ranged from 18 to 60 years old. Fifty-nine participants were female, and 41 were male. The study was carried out in different settings (in front of mosques and Moroccan cultural associations, and on the campus of a French University). Participants completed a short questionnaire under the supervision of the researcher of Moroccan origin. 


\subsubsection{Measures}

Participants gave their responses on scales ranging from 1 (strongly disagree) to 7 (strongly agree). The questionnaire included measures of assimilation, citizenship, secularism, multiculturalism and evaluations towards French and Moroccans (see below).

The assimilation measure was based on previous research (e.g. Badea, 2012) and contained six items such as "immigrants must adopt French customs and traditions" and "French Nation must be considered as one nation, indivisible". After reverse-coding the negative items, participants' ratings on the six items were averaged to form an overall assimilation score (Cronbach's alpha $=0.87$ ). Higher scores indicate greater endorsement of assimilation.

The construct of citizenship was measured by four items (e.g. "French society is composed of citizens rather than of communities" - Kamiejski et al., 2012). The scale had a satisfactory internal consistency (Cronbach's alpha $=0.85$ ). Higher scores indicate greater levels of citizenship.

Secularism was assessed by asking the participants to respond to six items. The questions were taken from pre-vious studies conducted in France (see Kamiejski et al., 2012). The items measured the desire to restrict to a private sphere the manifestation of belonging to a specific religion (e.g. "For me it is normal that religious signs are forbidden in state schools"). Cronbach's alpha for the eight-item scale was 0.89. A higher score indicates a stronger endorsement of secularism.

Eight items assessed the endorsement of multiculturalism ideology. These items were developed by Berry and Kalin (1995) and have already been used in studies carried out in France (Badea, 2012; Kamiejski et al., 2012). The scale contains items such as "The more cultural groups there are, the better it is for a society", and "National unity may be weakened by the attachments of ethnic groups to their original life style" (reverse coded). The eight-item scale was internally consistent with Cronbach's alpha of 0.89, with a higher score indicating a stronger endorsement of multiculturalism.

To assess group evaluations, we gave the participants a "feeling thermometer." This thermometer has been used in different studies of both majority and minority group participants, including studies in France (e.g. Guimond, 1999). It is intended as a global measure of in-group and out-group attitudes. The scale has a good level of (test-retest) reliability and correlates highly with measures using several items (Haddock, Zanna, \& Esess, 1994). The exact wording of the instructions was “Use the 'feeling-thermometer' to indicate whether you have positive or negative feelings about the following groups. You may mark any degree between 0 and $100.100^{\circ}$ indicates very positive or warm feelings, with zero degrees indicating very cold or negative feelings." Following this, several groups were listed (e.g. Jewish, Policemen, Portuguese), and among these were the Moroccan and French groups which were the two target groups of this study (see Judd, McClelland, \& Culhane, 1995).

Finally, participants provided information about their age, gender, level of education and mother tongue.

\subsection{Results and discussion}

Gender, age and mother tongue (French or Moroccan) did not affect any of the measures and were therefore not included as an independent variable in the analyses. Descriptive statistics are presented in Table 1.

Because adhesions to acculturation ideologies measured in this study were highly correlated (see also Badea, 2012; Kamiejski et al., 2012), a principal components analysis (with oblimin rotation) was conducted on all the acculturation items. The presence of four separate factors emerged: they represented, respectively, (1) multiculturalism (36.13\% of variance explained), (2) secularism (21.50\%), (3) assimilation (5.33\%) and citizenship (3.89\%), all eigenvalues $>1.35$. We then tested correlations between these factors and the group evaluations (Moroccans and French). As predicted, we found a negative correlation between adhesion to assimilation or secularism and in-group liking: the more immigrants preferred these ideologies, the less they showed a positive evaluation of Moroccan people, $r(101)=-0.65, p<0.001$, and respec-tively, $r(101)=-0.55, p<0.001$. No significant correlation between in-group liking and adhesion to multiculturalism or citizenship was noticed $(p>0.69)$. Adhesion to all these ideologies correlated positively with out-group liking, assimila-tion: $r(101)=$ $0.39, p<0.001$, secularism: $r(101)=0.35, p<0.001$, multiculturalism: $r(101)=0.34, p<0.001$, and citizenship: $r(101)=0.41$, $p<0.001$

Table 1

Means (standard deviations) and correlations between adhesion to acculturation ideologies and group evaluation in Study 1 .

\begin{tabular}{|c|c|c|c|c|c|c|c|}
\hline & Mean (std. deviation) & 1 & 2 & 3 & 4 & 5 & 6 \\
\hline 1. Assimilation & $2.93(1.59)$ & 1 & & & & & \\
\hline 2. Secularism & $2.92(1.77)$ & $0.69^{* *}$ & 1 & & & & \\
\hline 3. Multiculturalism & $3.55(1.72)$ & $-0.24^{*}$ & $-0.28^{*}$ & 1 & & & \\
\hline 4. Citizenship & $3.56(1.88)$ & $\begin{array}{l}-0.24 \\
-0.15\end{array}$ & $\begin{array}{l}-0.28 \\
-0.18\end{array}$ & $0.88^{* *}$ & 1 & & \\
\hline 5. In-group liking & $78.83(18.66)$ & $-0.155^{* *}$ & $\begin{array}{l}-0.10 \\
-0.55^{* *}\end{array}$ & 0.04 & -0.04 & 1 & \\
\hline 6. Out-group liking & $60.15(23.76)$ & $0.39^{* *}$ & $-0.35^{*}$ & $0.34^{*}$ & $-0.41^{* *}$ & $-0.35^{*}$ & 1 \\
\hline
\end{tabular}




\section{Study 2}

In this study, we experimentally manipulated acculturation ideologies and we measured perceptions of the legitimacy of the ideology, and group evaluations. In addition, we use an IAT to measure intergroup attitudes at an implicit level. Previous work has already shown that implicit intergroup attitudes can be sensitive to the social context (Richeson \& Nussbaum, 2004). We hypothesized that in-group liking would be lower than out-group liking in assimilation and secularism conditions compared to citizenship and multiculturalism conditions.

We then examined the role of how the legitimacy of an ideology is perceived in the link between ideologies and group evaluation. Immigrants might consider it to be justifiable that majority group members protect their national culture and impose assimilation. That might be result of socialization or, alternatively, an individual mobility strategy. We predicted that the effect of acculturation ideology on group evaluation would be mediated by the perception of legitimacy: immigrants in assimilation and secularism conditions would perceive these ideologies as being more legitimized than multiculturalism and citizenship. This is why immigrants showed less in-group liking in the first two experimental conditions.

\subsection{Methods}

\subsubsection{Participants}

The experiment was conducted with 110 Moroccans from Clermont-Ferrand. Participants were recruited via local contacts and their participation was requested for research on contemporary social issues. It took about 30-35 min to complete the questionnaire in French. There were 47 females and 63 males. The mean age was $31.65(S D=10.18)$, and age ranged from 17 to 56 . As in Study 1, the researcher was of Moroccan origin.

\subsubsection{Design}

An experimental between-subjects study was carried out. First, a text was administered randomly via a computer. There were four different versions of the text: one version focused on personal identity and the uniqueness of individuals (citizenship), another on multicultural recognition, a third focused participants' attention on the importance of assimilation, and a fourth version on the importance of secularism (see Appendix).

The experimental manipulation was set up in accordance with the procedure outlined by Wolsko, Park, Judd, and Wittenbrink (2000). Wolsko and his colleagues experimentally manipulated colour-blind versus multicultural ideology by providing participants with a one-page statement that endorsed either a colour-blind or a multicultural approach to inter-ethnic relations. Participants were subsequently asked to list five reasons why colour blindness (or multiculturalism) is an adequate approach to group relations (see also, Richeson \& Nussbaum, 2004; Verkuyten, 2010).

\subsubsection{Dependent measures}

The questionnaire included measures of perceived legitimacy, and group evaluations (explicit and implicit measures).

Perceptions of legitimacy. Participants were asked how unfair, justifiable, unjustifiable, legitimate and illegitimate was the acculturation ideology described in the text (Jost \& Burgess, 2000). All ratings were made on 7-point scales ranging from strongly disagree to strongly agree. A general index of perceived legitimacy was computed by averaging across the five items (Cronbach's alpha $=0.88$ ).

Group evaluations were measured using the same feeling thermometer as in Study 1. Again, the Moroccans and the French, the two target groups of this experiment, were listed along with other groups.

Group evaluations were also measured by the Implicit Association Test (Greenwald et al., 1998). Participants completed the IAT on a MAC laptop. Their task was to categorize Arab first names (e.g. Aïcha), French first names (e.g. Marie), negative traits (e.g. aggressive), and positive traits (e.g. warm). Order was counterbalanced across participants.

\subsection{Results and discussion}

Target group order did not affect any of the dependent variables and was therefore not included as an independent variable in the analyses.

Perceptions of legitimacy. Perception of legitimacy scores were submitted to a one-way (version of the text: multiculturalism, secularism, citizenship, assimilation) ANOVA between participants. There was a significant main effect of the version of the text, $F(3,106)=12.88, p<0.001, \eta^{2}=0.27$. Participants perceived assimilation $(M=4.86, S D=2.17)$ and secularism $(M=4.52, \mathrm{SD}=2.05)$ as being more legitimated than multiculturalism $(M=2.45, \mathrm{SD}=1.81)$ and citizenship $(M=2.35$, $\mathrm{SD}=1.67$ ), test $\mathrm{LSD} p<0.001$. Difference between assimilation and secularism, and between multiculturalism and citizenship were not significant, test LSD, $p>0.51$.

Group evaluations. Explicit evaluations were analyzed as a function of target group (Moroccans vs. the French) and the version of the text (multiculturalism, secularism, citizenship, assimilation). This resulted in a $2 \times 4$ mixed-design ANOVA with the first factor varying within participants and the second factor between them. The analysis of the explicit evaluation scores revealed a target group main effect, $F(1,106)=21.81, p<0.001, \eta^{2}=0.17$, such that, on average, French evaluations were more positive than Moroccan evaluations, $t(109)=4.26, p<0.001$. Interaction between the target group evaluations and the versions of the text was also significant, $F(3,106)=9.20, p<0.001, \eta^{2}=0.21$. Participants who read the texts on assimilation 
Perceived legitimacy and group evaluations as a function of experimental condition in Study 2 (means and standard deviations).

\begin{tabular}{cccc}
\hline & Multiculturalism & Citizenship & Secularism \\
\hline Perceived legitimacy & $2.45(1.81)$ & $2.35(1.68)$ & $4.52(2.06)$ \\
Explicit attitudes & & & $4.86(2.17)$ \\
In-group liking & $74.65(20.17)$ & $73.84(26.24)$ & $47.67(23.55)$ \\
Out-group liking & $76.55(18.13)$ & $69.23(27.56)$ & $73.71(20.81)$ \\
Implicit attitudes & $-0.14(.26)$ & $-0.12(.51)$ & $-0.49(.61)$ \\
\hline
\end{tabular}

$(M=47.44, \mathrm{SD}=22.21)$ or secularism $(M=47.67, \mathrm{SD}=23.54)$ expressed less in-group liking compared to participants who read text about citizenship $(M=73.84, \mathrm{SD}=26.24)$ or multiculturalism $(M=74.65, \mathrm{SD}=20.17)$, test $\mathrm{LSD}, p<0.001$. Differences between assimilation and secularism, and between multiculturalism and citizenship were not significant, test LSD, $p>91$.

No significant condition differences emerged on the out-group liking, assimilation $(M=72.41, \mathrm{SD}=23.03)$, secularism $(M=73.71, \mathrm{SD}=20.78)$, multiculturalism $(M=76.55, \mathrm{SD}=18.13)$, citizenship $(M=69.23, \mathrm{SD}=27.55)$, test LSD, $p>0.29(\mathrm{Table} 2)$.

IAT scores were computed using the improved scoring algorithm (Greenwald, Nosek, \& Banaji, 2003), which yields an effect size estimate (the IAT $d$ score, a variant of Cohen's $d$ ) for each participant. The $d$ score was computed by subtracting latencies for attitude-congruent trials (Moroccan and positive on one key, French and negative on the other key) from latencies for attitude-incongruent trials (Moroccan and negative on one key, French and positive on the other key) divided by the pooled standard deviation. The higher the $d$ score, the more it indicated a positive attitude towards the in-group relative to the out-group (i.e. more in-group liking).

The $d$ scores were analyzed using a one-way (version of the text: multiculturalism, secularism, citizenship, and assimilation) ANOVA between participants. There was a significant effect of the version of the text, $F(3,106)=3.64, p<0.02, \eta^{2}=$ 0.09. Participants showed less in-group liking if they had previously read the text about assimilation or secularism than the text referring to the importance of citizenship or multiculturalism, $t(106)=3.27, p=0.001$.

One important objective of the present experiment was to test the hypothesis that the effect of the experimental manipulation on group evaluation and on implicit attitudes was mediated by the participants' perception of legitimacy. In order to test these mediations, a group evaluation score was computed by subtracting the liking score for the French from the liking score for Moroccans. Higher scores mean greater in-group liking.

Following the guidelines proposed by Baron and Kenny (1986), a mediation model was then constructed to test whether perception of legitimacy mediates the effect of experimental condition on in-group liking and on implicit attitudes. The experimental condition was a contrast code: multiculturalism ( -1$)$, citizenship ( -1$)$, assimilation (1) and secularism (1). A simple regression analysis showed that the experimental condition significantly predicts in-group liking, $\beta=-0.45, p<$ 0.001: the more participants prefer assimilation and secularism over multiculturalism and citizenship, the less they show in-group liking. The experimental condition also significantly predicts perception of legitimacy, $\beta=0.51, p<0.001$ : participants per-ceive assimilation and secularism to be more legitimate than multiculturalism and citizenship. Moreover, in the regression in which the experimental condition and perception of legitimacy were both included as predictors, the effect of the experimen-tal condition was not significant, $\beta=0.06$, $n$, whereas the effect of perception of legitimacy remained significant, $\beta=-0.76, p<0.001$ (see Fig. 1). Regarding the mediation on implicit attitudes, the experimental condition also predicts both implicit attitudes, $\beta=-0.30, p=0.001$, and perception of legitimacy, $\beta=0.51, p<0.001$. The pattern of results was similar to that of explicit attitudes. In the regression, in which the experimental condition and perception of legitimacy were both included as predictors, the effect of the experimental condition was not significant, $\beta=$ $-0.06, n s$, and the effect of the mediator (perception of legitimacy) was significant, $\beta=-0.47, p<0.001$ (see Fig. 1 ).

We used an additional analysis in order to test our mediation model. We followed the recommendations of Preacher and Hayes (2008), who suggest using a bootstrapping procedure to compute a confidence interval around the indirect effect (i.e., the path through the mediator). In this analysis, a confidence interval that does not contain zero is equivalent to evidence for mediation at $p<0.05$. These analyses revealed that the effect of the experimental condition on group evaluation and

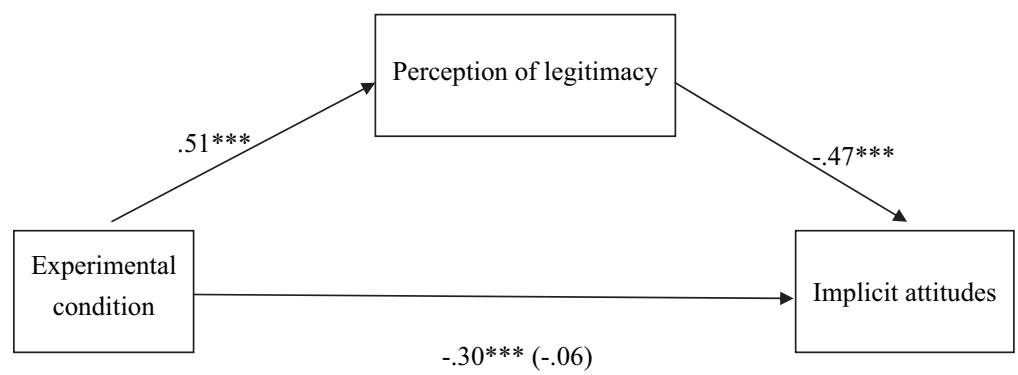

Fig. 1. Results of the regression analysis showing that the effect of experimental condition on in-group liking is mediated by perception legitimacy in Study 2 . The numbers are standardized regression coefficients. 
implicit attitudes was mediated by perceived legitimacy ( $95 \% \mathrm{CI}: 7.40-16.50$ and $95 \% \mathrm{CI}:-0.22$ to -0.06 , respectively) and by negative emotions towards Moroccans (95\% CI: $1.80-7.06$ and $95 \% \mathrm{CI}:-0.11$ to -0.02 , respectively) (see Fig. 1 ).

As expected, the effect of acculturation ideologies on group evaluation was mediated by perception of legitimacy at both explicit and implicit levels: The more immigrants adhere to assimilation or secularism, the more they perceive these models as being legitimized and the less they display in-group liking at explicit and implicit levels.

\section{General discussion}

The aim of this research was to examine the link between adhesion to different acculturation ideologies and group evaluation among Moroccan immigrants in France. Some of the acculturation ideologies defend equality between ethnic groups and individuals (i.e. multiculturalism, citizenship), while other ideologies promote the dominant position of the majority group (i.e. assimilation, secularism).

We have presented two studies. In the first study, we showed a negative correlation between adhesion to assimilation or secularism and in-group liking: The more immigrants preferred these ideologies, the less they showed a positive evaluation of Moroccans people. In the second study, we experimentally manipulated the acculturation ideologies by presenting immigrants with one of the four acculturation ideologies discussed in this paper and asking them to argue in favour of that ideology. We showed that in-group liking was lower in assimilation and secularism conditions compared to citizenship and multiculturalism conditions (see also, Verkuyten, 2005). No significant condition differences emerged on the out-group liking.

We also aimed to understand the effect of ideology adhesion on group evaluation by examining the legitimacy perception of these ideologies. We found a mediation of ideology effect on group evaluation by the perception of legitimacy: The more immigrants perceive assimilation or secularism as being legitimized, the more they show negative in-group evaluation. Implicit measures showed similar pattern of results such as explicit group evaluation (see also, Richeson \& Nussbaum, 2004). In-group liking was less important in the assimilation and secularism conditions compared to multiculturalism and citizenship. Again, this effect was mediated by the perception of legitimacy.

According to social identity theory (Tajfel \& Turner, 1986), the need for positive in-group distinctiveness is the key to understanding intergroup relations. Individuals derive their social identity from their membership of social groups, and that is why they prefer their in-group to be socially recognized and valued. Social identity theory recognizes that when there is a large consensus in the society regarding the superiority of the majority group, minority members are forced by the "social reality" to recognize their inferior status (Rubin \& Hewstone, 2004). We might therefore think that perception of the legitimacy of acculturation ideologies and its negative consequences on in-group evaluation can be result of immigrants' socialization in a context not favourable to immigration. However, there is some evidence that group evaluation at both explicit and implicit levels is sensitive to situational cues (e.g. Richeson \& Nussbaum, 2004) and do not simply reflect more stable underlying attitudes acquired in socialization. In Study 2, reading one text or another describing an acculturation ideology and justifying why the given acculturation ideology can improve intergroup relations has implications for immigrants' explicit and implicit attitudes. Dambrun et al., 2005 consider that intergroup bias at the implicit level expresses an "internalization" of negative in-group reputation. But in our Study 2, participants in assimilation and secularism conditions might show lower in-group liking not because they internalize this negative image of their group. Indeed, we did not measure their adhesion to acculturation ideologies. We made them think about one of these integration models. In this case, participants might simply show a congruent groups' evaluation with the salient acculturation ideology.

Alternatively, a strategy of individual mobility might be responsible for the findings (Guimond, 2010). We might suppose that immigrants who are in assimilation and secularism experimental conditions and who perceive these models as being legitimized are following a strategy of individual mobility. Immigrants' perception of the legitimacy of acculturation ideologies favourable to the host country (assimilation, secularism) and group evaluation might reflect their wish to be part of the majority group. However, a conclusion in favour of individual mobility strategy requires additional research which would also measure group identification and permeability of intergroup frontiers.

In these studies we do not distinguish between immigrants of first and second generations. Some Moroccan immigrants consider their mother tongue to be French, suggesting that they were second generation, but this factor did not correlate with our measurements. At the same time, in our studies participants were in a phase of cultural identity exploration, with ages ranging from 17 to 60 years old (Romero \& Roberts, 1998; Sabatier, 2008). These elements suggest that, in our sample, immigrant family dynamics played a less important role in group evaluation (Sabatier, 2008).

Future research should also examine the link between immigrants' adhesion to acculturation ideologies and their own acculturation strategies. Our results show that immigrants who adhere to assimilation and secularism ideologies show less in-group liking (see also Verkuyten, 2005). Does adhesion to assimilation and secularism prevent immigrants from developing an integration acculturation strategy via the reduction of in-group liking? Indeed, identity change literature shows that immigrants need to resolve the issue of how much they want to maintain their ethnic identity before determining their willingness to take on the new culture. This reasoning is consistent with acculturation literature, which also suggests that accepting one's own immigrant identity leads to more openness for the majority culture and other groups in general (see Phinney, Jacoby, \& Silva, 2007).

This research contributes to the literature examining factors which can shape immigrants' in-group evaluation and indirectly, their acculturation in a new country. Examination of acculturation should take into account the impact of socialization 
on immigrants' choices to preserve or not their original culture and to adopt or not the host culture. They also should take into account immigrants' social identity strategies.

\section{Appendix.}

Texts used for the manipulation of acculturation ideologies in Study 2.

\section{Assimilation}

Generally speaking, the French nation must be considered as a unity, one and indivisible. Like all French people, immigrants must therefore over time learn traditional French culture and French history. They will then adopt French customs and traditions. Living in France, they become naturally fluent in French, as did Italian and Portuguese immigrants before them. In appropriating French culture, they thus gradually and naturally set aside the customs and traditions of their country of origin and adopt those of their host country.

\section{Citizenship}

Generally speaking, French society consists before anything else of citizens and not of communities. One should not therefore define people in France according to their origins or their religion. A Frenchman must be considered as a unique individual and not as member of a particular community, or as an ethnic, religious or sexual being. Toput it more clearly, the French Republic considers individuals to be citizens before being black, white, young, old, people of NorthAfrican origin, women, men, gay or heterosexual.

\section{Secularism}

Generally speaking, as in most other countries, the division between religion and the State also exists in France. Indeed, religious practices have a private and not a public character. Visible religious signs are therefore forbidden in French state schools. Furthermore, whether one is Catholic (the cross) or Muslim (the veil), no religious signs must be visible on the French ID card. Public financing for the construction of religious buildings should also be prohibited.

\section{Multiculturalism}

Generally speaking, a society featuring a variety of cultural groups is more capable of facing any problems which might arise. French society should therefore accept the customs and the values of the various cultural groups living in France. If people who come to live in France have to learn French culture, immigrant parents must also encourage their children to preserve the culture and the traditions of their country of origin. It is therefore important that the authorities help ethical minorities to protect their cultural heritage. French people and immigrants can live in the same districts and the different ethnic groups must preserve their lifestyles.

\section{References}

Antonova, V. K. (2005). The state of multiculturalism in Russia. Essex Graduate Journal of Sociology, 5, 46-55.

Badea, C. (2012). Modèles d'intégration, identification nationale et préjugés envers les immigrés en France. L'Année Psychologique, 112, 575-592.

Badea, C., Jetten, J., Iyer, A., \& Er-rafiy, A. (2011). Negotiating dual identities: The impact of group-based rejection on identification and acculturation. European Journal of Social Psychology, 41, 586-596.

Baron, R. M., \& Kenny, D. A. (1986). The moderator-mediator variable distinction in social psychological research: Conceptual, strategic, and statistical considerations. Journal of Personality and Social Psychology, 51(6), 1173.

Baubérot, J. (2010). Introduction. La laïcité en France entre mémoire et histoire. Paris: P.U.F.

Berry, J. (2006). Contexts of acculturation. In D. Sam, \& J. W. Berry (Eds.), The Cambridge handbook of acculturation psychology (pp. 27-42). Cambridge: University Press.

Berry, J., \& Kalin, R. (1995). Multicultural and ethnic attitudes in Canada: An overview of the 1991 National Survey. Canadian Journal of Behavioural Science, 27(3), 301-320.

Bourhis, R., Moïse, C., Perreault, S., \& Senecal, S. (1997). Towards an interactive acculturation model: A social psychological approach. International Journal of Psychology, 32, 369-386.

Dambrun, M., Gatto, J., \& Roche, C. (2005). L'effet du statut du groupe d'appartenance sur les attitudes ethniques implicites et explicites chez les enfants. Les Cahiers Internationaux de Psychologie Sociale, 3, 65-76.

Ellemers, N. (2001). Individual upward mobility and the perceived legitimacy of intergroup relations. In J. Jost, \& B. Major (Eds.), The psychology of legitimacy: Emerging perspectives on ideology, justice, and intergroup relations (pp. 205-222). Cambridge: Cambridge University Press.

Ellemers, N., Spears, R., \& Doosje, B. (2002). Self and social identity. Annual Review of Psychology, 53, 161-186.

Greenwald, A., McGhee, D., \& Schwartz, J. (1998). Measuring individual differences in implicit cognition: The implicit association test. Journal of Personality and Social Psychology, 74, 1464-1480.

Greenwald, A., Nosek, B., \& Banaji, M. (2003). Understanding and using the implicit association Test: I. An improved scoring algorithm. Journal of Personality and Social Psychology, 85, 197-216.

Guimond, S. (1999). Attitude change during college: Normative or informational social influence? Social Psychology of Education, 2, $237-261$.

Guimond, S. (2010). Psychologie sociale: Perspective multiculturelle. Paris: Editions Mardaga. 
Guimond, S., de la Sablonnière, R., \& Nugier, A. (2014). Living in a multicultural world: Intergroup ideologies and the societal context of intergroup relations. European Review of Social Psychology, 25(1), 142-188.

Guimond, S., Dif, S., \& Aupy, A. (2002). Social identity, relative group status, and intergroup attitudes: When favorable outcomes change intergroup relations. . . for worse. European Journal of Social Psychology, 32, 739-760.

Guimond, S., \& Palmer, D. L. (1993). Developmental changes in ingroup favouritism among bilingual and unlingual francophone and Anglophone students. Journal of Language and Social Psychology, 12, 318-351.

Haddock, G., Zanna, M., \& Esess, V. (1994). Mood and the expression of intergroup attitudes: The moderating role of affect intensity. European Journal of Social Psychology, 24, 189-205.

Jost, J. T., \& Banaji, M. R. (1994). The role of stereotyping in system justification and the production of false consciousness. British Journal of Social

Psychology,

$33,1-27$

Jost, J. T., \& Burgess, D. (2000). Attitudinal ambivalence and the conflict between group and system justification motives in low status groups. Personality and Social Psychology Bulletin, 26(3), 293-305.

Jost, J. T., Pelham, B. W., \& Carvallo, M. R. (2002). Non-conscious forms of system justification: Implicit and behavioral preferences for higher status groups. Journal of Experimental Social Psychology, 38, 586-602.

Judd, C., McClelland, G., \& Culhane, S. (1995). Data analysis: Continuing issues in the everyday analysis of psychological data. Annual Review of Psychology, $46,433-465$.

Kamiejski, R., Guimond, S., De Oliveira, P., Er-rafiy, A., \& Brauer, M. (2012). Le modèle républicain d'intégration: Implications pour la psychologie des

relations entre groupes. L'Année Psychologique, 112, 49-83.

Le Monde. (2013). Trappes: le récit d'un week-end sous tension. Retrieved from http://www.lemonde.fr/societe/article/2013/07/22/trappes-les-raisons-de-lacolere $34508893224 . \mathrm{html}$

Levin, S., Matthews, M., Guimond, S., Sidanius, J., Pratto, F., Kteily, N., et al. (2012). Assimilation, multiculturalism, and colorblindness: Mediated and moderated relationships between social dominance orientation and prejudice. Journal of Experimental Social Psychology, 48, $207-212$.

Mackie, D. M., Hamilton, D., Susskind, J., \& Rosselli, F. (1996). Social psychological foundations of stereotype formation. In C. N. Macrae, C. Stangor, \& M. Hewstone (Eds.), Stereotypes and stereotyping (pp. 41-79). New York: The Guilford Press.

Phinney, J. S., Jacoby, B., \& Silva, C. (2007). Positive intergroup attitudes: The role of ethnic identity. International Journal of Behavioral Development, 31, $478-490$.

Preacher, K. J., \& Hayes, A. F. (2008). Asymptotic and resampling strategies for assessing and comparing indirect effects in multiple mediator models. Behavior Research Methods, 40, 879-891.

Ramos, M., Jetten, J., Airong, T., Badea, C., Iyer, A., \& Cui, L. (2013). Minority goals for interaction with the majority: Seeking distance from the majority and the effect of rejection on identification. European Journal of Social Psychology, 43, 72-83.

Reicher, S., \& Levine, M. (1994). On the consequences of deindividuation manipulations for the strategic communication of self: Identifiability and the presentation of social identity. European Journal of Social Psychology, 24, 425-524.

Richeson, J. A., \& Nussbaum, R. J. (2004). The impact of multiculturalism versus color-blindness on racial bias. Journal of Experimental Social Psychology, 40, $417-423$.

Romero, A. J., \& Roberts, R. E. (1998). Perception of discrimination and ethnocultural variables in a diverse group of adolescents. Journal of Adolescence, 21(6), 641-656.

Rubin, M., \& Hewstone, M. (2004). Social identity, system justification, and social dominance: Commentary on Reicher, Jost et al., and Sidanius et al.

Political Psychology, 25(6), 823-844.

Sabatier, C. (2008). Ethnic and national identity among second-generation immigrant adolescents in France: The role of social context and family. Journal of Adolescence, 31(2), 185-205.

Sabatier, C., \& Boutry, V. (2006). Acculturation in francophone European societies. In D. L. Sam, \& J. W. Berry (Eds.), The Cambridge handbook of acculturation psychology. Cambridge: Cambridge University Press.

Sam, D. L., \& Berry, J. W. (2006). The Cambridge handbook of acculturation psychology. Cambridge: Cambridge University Press.

Spears, R., Jetten, J., \& Doosje, B. (2001). The (il)legitimacy of ingroup bias: From social reality to social resistance. In J. Jost, \& M. Brenda (Eds.), The psychology of legitimacy: Emerging perspectives on ideology, justice, and intergroup relations (pp. 332-362). New York: Cambridge University Press.

Tajfel, H., \& Turner, J. C. (1979). An integrative theory of intergroup conflict. In W. G. Austin, \& S. Worchel (Eds.), The social psychology of intergroup relations (pp. 33-47). Monterey, CA: Brooks Cole.

Verkuyten, M. (2005). Ethnic group identification and group evaluation among minority and majority groups: Testing the multiculturalism hypothesis. Journal of Personality and Social Psychology, 88, 121-138.

Verkuyten, M. (2010). Assimilation ideology and situational well-being among ethnic minority members. Journal of Experimental Social Psychology, 46, 269-275.

Wolsko, C., Park, B., \& Judd, C. M. (2002). The measurement and consequences of interethnic ideology. Boulder, CO: University of Colorado.

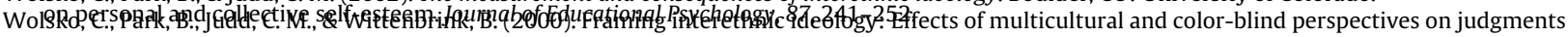
of groups and individuals. Journal of Personality and Social Psychology, 78, 635-654.

Wright, S. C., \& Taylor, D. M. (1995). Identity and the language of the classroom: Investigating the impact of heritage versus second language instruction 